British Journal of Psychiatry (1989), 155, 865-872

\title{
Correspondence
}

Editor: Ian Pullen

Contents: The myth of hysteria as illness/Comparison of diazepam and buspirone/ASC and water intoxication/Better to be depressed in the sun/Selfharm and depressive disorder/Brain white-matter lesions and psychosis/Trichotillomania/Failure to convulse with ECT/Spontaneous orgasms - an explanation?/Pseudodementia/Beclomethasone mania

\section{The myth of hysteria as illness}

SIR: If a restaurant served perfectly good food but the sign outside declared that it was all poisoned, even the hungriest customer would keep away. If the poison sign was removed, crowds would pack in. I wish to welcome and emphasise the equally dramatic implications of Birtchnell's reconsideration (Journal, September 1989, 155, 425-429) of The Myth of Mental Illness (Szasz, 1961).

Like Dr Birtchnell, I have always felt it should go under a more modest and accurate title; my choice would be The Myth of Hysteria as Illness. In the book (this one, anyway), Szasz only minimally suggests that the argument applies across all that we call mental illness. As a private practitioner of psychoanalysis, he rightly kept to his area of expertise normal and neurotic, not psychotic. Admittedly, the infamous title does represent what he has since argued, and the book would certainly not have sold so massively to a general public under a modest title.

By an interesting coincidence, the same issue of the Journal contains Taylor's excellent exploration of 'Hysteria, belief and magic' (Journal, September $1989,155,391-398$ ) in which he repeats and expands on this same 'point of view' - that psychiatrists strangely mirror the hysteric by wishing to label and treat hysteria as if it were a disease when by definition there is none (Taylor, 1986). Taylor (1982) has also developed a more discriminating framework than our medically rooted diagnostic system, which treats everything as if it belonged in the realm of 'bioscience'.

Dr Birtchnell refers to other authors interested in the realm of 'personal conduct' and 'interpersonal' theory and diagnosis. One quite concrete form of interpersonal assessment in ordinary psychiatric interviews (Child, 1983a) has supported the hypothesis that hysterical personality (if not hysteria) is best considered in interpersonal terms, and that such labels are attached to patients who are 'disagreeable' in general, and specifically in the patterns of looking and speech in the psychiatric interview (Child, 1983b). So Dr Taylor's ideas may be considered more substantial than just a 'point of view'.

The surprising conclusion about Szasz's infamous book is that the very psychiatrists (organicists) who believe it to be so poisonous by its outward sign are likely to find most food for thought inside, for they too hold that hysterics are not truly ill and so are not worthy of the attention they seek from psychiatrists. Unfortunately, therefore, the organicists' potential sympathy for Szasz's basic thesis does not characteristically extend to the patients themselves, and consequently organicists may not really be interested in a model of human conduct such as Szasz sets out in the book. So they may choose another 'restaurant' to eat in. But without its poisonous 'sign', at least they will respect, recommend and possibly even sample 'Café Szasz' rather than avoid and slander it.

The late R. D. Laing got his signs right and his recipes exotic but brilliant. His anti-establishmentarianism gained him the same popularity and infamy as Szasz. If he had wished to be taken more seriously by psychiatrists, I would have given him tactical advice in the same vein as renaming Szasz's book. Strategically, Laing should first have emphasised his ideas as applying to normal or neurotic functioning, not to psychotic - and certainly not as a cause of psychosis, however valid that suggestion might also be.

There are other instances of mistaken 'public relations' in this area of psychiatry, all the more astonishing because the mistakes have been made by the very people who are claiming superior skill in communication and interpersonal strategy. Bettelheim (1983) showed how Freud's translators converted ordinary German words into strange technical terminology in English, forever annexing much of the easily comprehensible 'soul' in his work. However, unlike Szasz, Laing and the others, Freud did want to establish a biological basis for psychoanalysis. 
Poor tactics are evident even in the banners under which proponents of the various 'psychotherapies' stand. The term 'therapy' is obviously meant to match physical 'therapies', thereby obtaining equal status with the likes of organic psychiatry, surgery, and medicine in lecture programmes and health services. Equal status there should certainly be. But unfortunately, 'therapy' also contains all the other implications that go with a 'bioscientific' approach. However little surgeons and physicians know about psychiatry and psychotherapy, they do know that they are operating in quite a different realm, and they instinctively resist.

So the psychotherapies are hoist by their own petard. For example, it is much easier with physical therapies to tell whether the patient has taken the doctor's advice or not. Of course, psychotherapy is more than just advice-giving, but a lot of it is about 'resistance' of various kinds. In the (inevitable) absence of concrete description or 'markers' of what happens in the interactions and process of psychotherapy, mere attendance for appointments may be equated with $100 \%$ compliance with treatment. Attending appointments on its own would never be a sufficient criterion for assessing the efficacy of a physical treatment. Again, the sign outside the restaurant has promoted decades of serious misunderstanding - and it is not really the outsiders' fault.

With this belated clarification, I commend fellow psychiatrists who have previously and understandably been repelled from entering some fine restaurants in our quarter of town, to shut their eyes to the misleading (and now immovable) signs outside, and feast within!

Child and Family Clinic

49 Airbles Road

Motherwell MLI 2TJ

Scotland

\section{References}

Betrelheim, B. (1983) Freud and Man's Soul. London: Chatto and Windus, The Hogarth Press.

CHILD, N. J. (1983a) Patterns of looking and speech in psychiatric interviews: 1. Description. British Journal of Clinical and Social Psychiatry, 2, 43-46.

(1983b) Patterns of looking and speech in psychiatric interviews: 2. Their functions. British Journal of Clinical and Social Psychiatry, 2, 66-71.

Szasz, T. S. (1961) The Myth of Mental Illness: Foundations of a Theory of Personal Conduct. New York: Hoeber-Harper. Also London: Paladin (1972).

TAYLOR, D. C. (1986) Hysteria, play-acting and courage. British Journal of Psychiatry, 149, 37-41.

TAYLOR, D. C. (1982) The components of sickness: diseases, illnesses and predicaments. In One Child (eds J. Apley and C. Ounsted) pp. 1-13. London: Spastics International Medical Publications/ Heinemann Medical Books.

\section{Comparison of diazepam and buspirone}

SIR: In the past year British psychiatrists have received concentrated advertising designed to persuade them to prescribe buspirone for anxiety. It has been hinted that buspirone is less likely to lead to dependence than diazepam. Murphy et al (Journal, April 1989, 154, 529-534) continue this theme.

Dr Murphy et al had four active treatment groups, each with only ten patients completing. There was no placebo group. The striking thing about their displayed results is that patients in all groups got better with the passage of time and the receiving of attention. At the end of 14 weeks, whether patients had had no active treatment for the past eight weeks or no active treatment for the past two weeks, as groups they were all much improved and did not differ from one another. Nor, one may suppose, would they have differed from a placebo group.

While anxiety levels were still initially high, and before time could have brought resolution, diazepam was significantly superior to buspirone in anxiety relief. There was also clear evidence of withdrawal effects after diazepam.

Dr Murphy et al have demonstrated again that diazepam is effective and that a drug effective against anxiety will lead to eventual withdrawal symptoms. Buspirone, not being noticeably effective, did not lead to noticeable withdrawal effects. Lack of potency of buspirone is no recommendation for its prescription.

University Department of Psychiatry

IAN OsWALD

The Kennedy Tower, Royal Edinburgh Hospital

Morningside Park

Edinburgh EHIO 5HF

\section{ASC and water intoxication}

SIR: I would like to thank and clarify the interesting points raised by Cooney (Journal, August 1989, 155, 266) regarding our case report (Lee et al, Journal, April 1989, 154, 556-558). Dr Cooney expressed surprise at our suggestion that we were not aware of previous reports of the use of water to induce an altered state of consciousness (ASC), for three reasons: (a) many of his patients with excessive fluid intake presented as 'drunk'; (b) case 1 in Singh et al (1985) turned to excessive water drinking because it made him feel slightly drunk; and (c) Ripley et al (1989) remarked that mild overhydration may be experienced as pleasurable, leading to further polydipsia.

The first observation is based on Dr Cooney's unpublished personal experience, and should not 